lished medical opinion in this country, which regarded the prescribing of narcotic drugs as incorrect for the treatment of addiction. This dilemma is still present-namely, that the majority of doctors question prescribing as a policy in this treatment. Experience has shown, however, that greater disasters occur when these drugs are available only illegally. Moreover, from the initial contact the doctor is able to limit other illness, by making available sterile needles, syringes, and water to people who are going to give themselves intravenous injections whatever the doctor may feel about it.

Nevertheless, the disease itself still remains an unsolved and serious socio-medical problem, which needs every experienced or interested doctor to help solve it. From the start, therefore, we have built up a team of two doctors, a social worker, an occupational therapist, a psychologist, a chaplain, a probation officer, biochemists, and a clinical pathologist, together with an independent clinical evaluator to assess our successes and failures.
Treatment centres of varying kinds could and should be piloted. Only after various types of treatment have been tried shall we be able to decide whether any amendments in the law are necessary.

I wish to make a very strong plea that all new treatment programmes for narcotic addiction should be approached experimentally. "Legislation establishing such programmes should be broadly framed and sufficiently flexible to permit testing of a variety of approaches, and to permit changes based on on-going experience." 5

\section{P. A. L. Chapple.}

\section{REFERENCES}

Bewley, T., Lancet, 1965, 1, 808

2 Dole, V. P., and Nyswander, M. E., N.Y. St. F. Med., 1966, 66, 2011. s Marks, V., and Chapple, P. A. L., Brit. f. Addict., 1967, 62, 189.

- Chapple, P. A. L., Excerpta Medica, in press.

- Isbell, H., in Proceedings White House Conference on Narcotic and Drug Abuse, September 1962, 1963. Washington.

\title{
Integrated Approach
}

\author{
From Dr. Fohn Owens, Consultant Psychiatrist, All Saints' Hospital, Birmingham
}

There are, I believe, two fundamental errors in current thought with regard to narcotic addiction in the U.K. Both are derived from the terms of reference of the Brain Committee in the first instance-from the exclusively medical composition and from its two reports. Firstly, there is the implicit assumption that heroin addiction is an entity in itself-in pure culture as it were uncontaminated by other drug-taking-and, secondly, there is the notion that narcotic addiction is exclusively a medical matter. These two misconceptions dominate and thus distort all thinking and planning about this phenomenon-this contagious disease of adolescence. They cause, I believe, clinicians to take up a denervating position and to indulge in sterile controversy. Much of the uncritical comment of treatment centres, for example, seems more concerned with fighting colleagues in medical administration than with sitting down and making a determined effort to study the local problem and consider how the treatment centre idea or the concept of treatment centres can be modified and applied in terms of local circumstances. One has fears for treatment centres-for example, one dreads that they will merely become prescribing centres rather than as envisaged in the Second Report of the Interdepartmental Committee. We would then merely be transferring the prescribing from a few general practitioners to a large number of unskilled hospital staff, possibly junior medical staff delegated to this chore and possibly poorly motivated. Such a situation will certainly not reduce the amount of heroin available.

Narcotic addiction must be regarded primarily as a problem of community mental health, the prime objectives of treatment being firstly the treatment of the individual addict, and secondly the containment of the number of established addicts to narcotics. This can be achieved through the creation of a therapeutic team which will aim at a long-term continuous sympathetic contact with the individual patient, to establish motivation and to protect and guide through rehabilitation. Such a programme of long-term care should be directed from an addiction unit which is $(a)$ interested in the treatment of all manner of addictions, and concerned to build up a body of knowledge about such states, and (b) would attempt to develop a centre for the treatment of heroin addiction within such a setting.

I consider that it is essential that any such addiction unit should develop an association with general psychiatric facilities of all kinds, including day care, industrial rehabilitation resources, and access to long-stay psychiatric beds. In view of the frequency of physical complications of addiction, closest cooperation with a general physician is paramount, while collaboration and continuity of care should be ensured through joint junior medical-staff appointments. It seems to me that

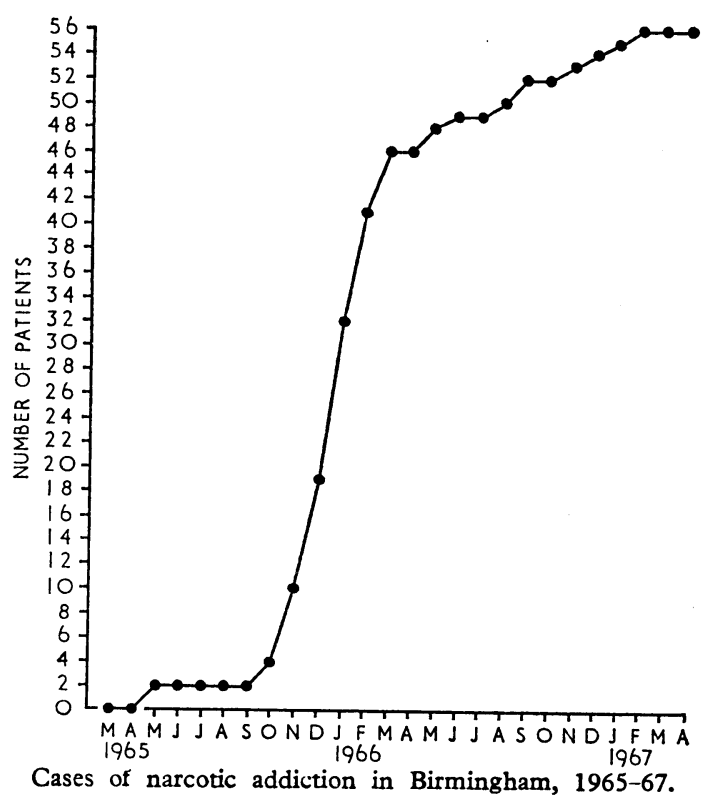

any treatment centre being newly created to deal with an established heroin problem would require the following: $(a)$ a welldefined catchment area; $(b)$ a system of registration of addicts for that area ; and (c) a system of identification of addictsthis may require to be in the nature of identity cards, and such a centre must refuse to deal with addicts from any other areas unless they are formally transferred. Further $(d)$ a number of pharmacists in that area should be asked to co-operate in the scheme and should have an allocation of addicts to a certain number; $(e)$ there should be created within each area a drug squad which would see its job in terms which one would call therapeutic, to identify cases of drug-takers and to prevent drug abuse ; $(f)$ such a unit would require a number of assessment 
beds, together with separate outpatient facilities, if only in terms of waiting-rooms.

I would also suggest that it is imperative for the successful containment of the heroin-addiction problem that there should be a maximum control of the amount of heroin available on prescription, and that this control can be achieved only through a rather rigid structuring of treatment centres. This would not in itself vitiate the maximum concern which one has clinically for the individual addict. There is perhaps a more important general and national issue to be decided, and this arises from the number of statutory agencies involved and the number of voluntary associations active in the field. The situation now demands that there be appointed someone with powers to control and to integrate all measures to deal with the narcoticaddiction problem.

The functions of a treatment centre are then, as I see it, (1) the containment of the number of addicts and the prevention of further cases being created; (2) the treatment of the individual addict, which demands a high degree of co-operation between physician, psychiatrist, and nursing staff ; (3) provision of leadership necessary to create a therapeutic team, working closely in continuous care of the individual addict within and without the treatment centre; (4) the conduct of research, much of which initially must be of a fact-finding nature (to this end there is the need for an accepted system of records, which might well be tied up with the system of identification of addicts); (5) to offer education in this field to postgraduate doctors, nurses, health visitors, probation officers, and other key people in the community who could influence the climate of opinion against indiscriminate drug-taking.

These thoughts on the development of treatment centres arise from our two years' experience and it can be seen from the accompanying graph that we have in fact contained the problem of narcotic addiction in Birmingham (compare with the national graph).

JOHN OWENS.

\section{CONFERENCES AND MEETINGS}

\section{Collection and Handling of Medical Data}

\section{[From a Special Correspondent]}

A symposium was held on the collection and handling of medical data at the University of Salford on 6 May, under the chairmanship of Sir EDward Collingwood, F.R.S. (Treasurer, Medical Research Council). Opening the conference, Dr. B. Richards (Manchester University Institute of Science and Technology) described some of the equipment available, pointing out that at present medical computing was the most expensive kind of activity in which doctors could indulge. In his view computer technology was now well ahead of requirements, and the next revolution must come from the users. For example, equipment available at present included a line printer, whose output was 2,400 lines per minute, and optical character readers which could cope with 100 documents per minute. Co-ordination between the Ministry of Health and the National Computing Centre would ensure that no duplication of computer programmes would occur in future.

\section{Medical Computing in the U.S.A.}

Describing some impressions of medical computing in the U.S.A., Dr. D. E. ClakK (Director of Medical Computation, University of Manchester) said that experience in that country went back to 1957 . At present all medical schools there had at least one computer, and in many centres students were being taught to use them. Already the longterm benefits of using computers and automated laboratory procedures had been found to be considerable-including raising the bed usage in a children's hospital from $85 \%$ to $95 \%$, reducing blood wastage, and lowering the cost of a battery of 10 laboratory tests from 15 dollars to 1.25 dollars. By 1980 Dr. Clark predicted that half the doctors graduating would have some knowledge of medical computing, while by 1970 the number of computers in American hospitals was expected to rise to 1,000 . Another project was that five major centres would be set up in the next few years for literature retrieval, in association with Medlars, which was shortly to be expanded.

The use of computers as an aid to diagnosis was discussed by Dr. Patricia $M$. FRASER (Royal Free Hospital, London), who described an attempt to derive " profiles" of various forms of liver disease using features derived from the patient's case history, the results of physical examination, and the results of laboratory, radiological, and special investigations. So far the results had not been sufficiently in agreement with current medical knowledge to be useful, and when many other features based on the result of liver-biopsy examination were added the confusion had become worse. In future work it was planned to adopt a weighting system for the individual features used in the study similar to that which had been used in the Medical Research Council leukaemia trial.

\section{Chromosome Analysis}

Some work in progress on techniques of computer recognition of chromosomal patterns was described by Miss J. Hilditch and Dr. D. Rutovitz (Clinical Effects of Radiation Research Unit, M.R.C. London and Edinburgh). They pointed out that conventional techniques of this kind might take up to 20 minutes for each cell studied, and, moreover, a large number of cells had to be scrutinized. This made large-sca'e surveys difficult-either of population genetics (where a large number of people had to be studied), or of environmental damage (where a large number of individual cells had to be examined in order to determine the true incidence). Automatic chromosome analysis would involve at least two stages: firstly, a search phase (when a suitable cell was being found), and, secondly, an analysis phase (when the individual cell would be scrutinized). Two particular problems needing solution at present were, firstly, how to distinguish by an automatic device the chromo- somal pattern from some extraneous object, and, secondly, the analysis of chromosomes that were bent or overlapped other chromosomes.

The use of computers in the biochemistry laboratory was discussed by Dr. T. P. WhiteHEAD (Queen Elizabeth Hospital, Birmingham). In 1960 his laboratory had been faced with well-known problems, such as overcrowded working space, a work-load that doubled every five years, and skilled scientific workers spending a third of their time in routine clerical work. On analysis there were three obvious main bottle-necks in the work: firstly, the transport of specimens and reports from the ward to the laboratory and vice versa; this had been rationalized by a work-study programme. Secondly, the analytic procedures; the length of time spent on these had been reduced by automation. The third bottle-neck was the clerical work, which had involved five separate pieces of paper being handled; this had been tackled with the computer. Dr. Whitehead considered that the advantages of automatic procedures and mechanization in the laboratory included accurate identification of the specimen, the analysis of a series of reports for the clinician, and a check on the workings of the laboratory itself. He suggested that a great deal of information lay hidden in laboratory data which could be revealed only by using the computer-for example, in his laboratory this had altered their views on the true range of the serum potassium concentration, as well as reminding them of the differences in the serumpotassium concentrations between males and females. At present a trial was in progress in his hospital whereby one blood specimen from some of the patients would be routinely examined by about 16 biochemical and five haematological investigations. Already this procedure had been found to be remarkably cheap, and Dr. Whitehead thought that it might well lead to better turnover of patients in the hospital. 